\title{
Physical - Chemical Profile of Kombuchas Marketed in the Governador Valadares City - Brazil
}

\section{Nayara Ferreira Zagnoli ${ }^{1}$, Thays Luke Archangel ${ }^{1}$, Victórya Soares Ávila ${ }^{1}$, Vitória Oliveira Silva Paes ${ }^{1}$, Najara Souza da Silva ${ }^{2}$, Ana Clara De Alvarenga Morais ${ }^{3}$, Eloisa Helena Medeiros Cunha ${ }^{4}$ and Anderson Ferreira Vilela ${ }^{5 *}$}

${ }^{1}$ Nutrition Student Vale do Rio Doce University UNIVALE - Governador Valadares-MG, Brazil

${ }^{2}$ Master's Student in Food Science and Technology at the Federal University of

Tocantins, Brazil

${ }^{3}$ Nutritionist, Master in Agri-Food Technology, Professor at the Vale do Rio Doce

University UNIVALE - Governador Valadares-MG, Brazil

${ }^{4}$ Nutritionist, Master in Nutrition and Health, Professor at the Vale do Rio Doce

University UNIVALE - Governador Valadares-MG, Brazil

${ }^{5}$ Pharmaceutical, PhD in Process Engineering, Professor at the Federal University of Paraíba, Bananeiras-PB, Brazil

*Corresponding Author: Anderson Ferreira Vilela, Pharmaceutical, PhD in Process Engineering, Professor at the Federal University of Paraíba, Bananeiras-PB, Brazil.
Received: November 25, 2021

Published: December 20, 2021

(C) All rights are reserved by Anderson

Ferreira Vilela., et al.

\begin{abstract}
Kombucha is a drink typically made of green or black tea, as well as needs the fermentation coming from an association of microorganisms beneficial to health. The consumption of Kombucha has become more frequent, since it brings vast benefits to health, as well as preventing cardiovascular diseases, promoting digestive functions, stimulating the immune system, reducing inflammatory problems. The objective of this work was to evaluate the physical-chemical parameters of Kombucha samples sold in the city of Governador Valadares-MG. This was a qualitative and quantitative experimental type of analytical study, where pH, humidity, ashes, sugars and antioxidants were analyzed. The results obtained showed moisture values according to the standards required by current legislation, no indicative legislation was found for ash values, also showed ideal pH values for Kombucha according to current legislation, presence of ascorbic acid, small amount of reducing and non-reducing sugars and presented satisfactory results for consumption. Therefore, it is of great importance to encourage the consumption of the beverage since it presents benefits for health and quality of life.
\end{abstract}

Keywords: Kombucha; Fermentation; Microorganisms; Physical-chemical Analysis

\section{Introduction}

The search for a healthier lifestyle has grown, and has been showing more and more that the current consumer is no longer only prioritizing the sensory aspects of a given product, but is also interested in seeking the benefits and functionalities that these products can offer to their health [1].
With this it is possible to notice a growing search for foods with functional properties [2], that is, those that, according to the National Health Surveillance Agency (ANVISA), when consumed as part of a usual diet, produce metabolic and/or physiological effects beneficial to health, being considered safe for consumption without medical supervision [3]. 
Faced with this search for a healthier lifestyle, there was an increase in kombucha consumption by the world population [4].

Kombucha is a refreshing, sweet and carbonated drink obtained by fermentation of sugary tea with a probiotic culture of acetic bacteria and fungi, consumed for its beneficial effects on human health. Research indicates that the drink can prevent cardiovascular diseases, promote digestive functions, stimulate the immune system, reduce inflammatory problems [5].

Among the main functions are: antioxidant action, glycemic index control and cancer prevention; due to the presence of vitamins, polyphenols and acids such as lylucconic acid, glycanic acid and lactic acid, as well as amino acids and other micronutrients produced during fermentation [6].

The main organic acids present in the fermented beverage are citric, folic, glyconic,glyconic, lactic, malic, malic, oxalic, pyruvic, succinic, tartaric acids. These acids and the sugars present will give the characteristic flavor of the drink $[7,8]$.

The acids and other products formed interact with the compounds of the tea used, thus producing new biologically active products, including amino acids and vitamins, predominantly of the B complex [9].

The B-complex vitamins found in higher concentrations are: Thiamine (B1), Riboflavin (B2), Pyridoxine (B6) and Cobalamin (B12), acting in metabolic reactions, collaborating as coenzymes in the process of energy production for the body [10]. In addition to these, it has vitamin $\mathrm{C}$, which has a direct influence as antioxidants and anti-inflammatory drugs that will bring benefits to the body in the fight against free radicals [11].

Fermented tea also contains significant levels of antioxidants, substances with ability to action account for physiological oxidative stress and catechins, one of the few groups of flavonoid compounds that have significant bioavailability [6].

The sugar added to the tea serves as food for scoby crops, glucose being the preferred substrate of these crops. The final concentration of sugar in the ready product may be different between fermentations, noting that the metabolic pathways of fermentation do not occur in the same way in all Kombuchas [5].

Kombucha has symbiotic property because it presents beneficial living microorganisms (probiotics) and prebiotics, which are fundamental in the balance of the intestinal microbiota $[12,13]$.
The microorganisms present in the drink will compete with pathogenic bacteria for sites of asion and nutrients, reduce the permeability of the intestine and control the intestinal microbiota, preventing food intolerances, bringing positive results to increased immunity, irritable bowel syndrome and other metabolic syndromes [14].

Since it is a beverage that is available for sale, both in supermarkets and in stores of natural products, it is of paramount importance to make a physical-chemical analysis of antioxidants, $\mathrm{pH}$, sugars and organic compounds present in Kombucha, thus allowing it to be possible to identify whether the product in question has a significant nutritional value [1].

Thus, the objective of this work was to evaluate the physical-chemical parameters such as moisture, ash, $\mathrm{pH}$, glucose reducing sugar and non-reducing sugar in sucrose, ascorbic acid and galates in strawberry-based Kombuchas samples, commercialized in the municipality of Governador Valadares- Minas Gerais.

\section{Material and Methods}

Location and search period

The research was carried out at the Center for Health Sciences at Vale do Rio Doce University (UNIVALE), located in the city of Governador Valadares-MG, in the Pharmacognesia Laboratory. Kombuchas were collected and analyzed from September to October 2020.

\section{Acquisition of raw materials}

A survey was made of the available brands of Kombucha for sale in the trade of Governador Valadares, and later was punctuated all the flavors that each brand contained. From the list of flavors that each brand contained, a flavor was chosen that all presented in common. The base flavor chosen was strawberry.

Four types of different commercial trademarks of Kombuchas were collected, acquired in the shops of the Municipality of Governador Valadares-MG, using the consumer's availability criteria to find these Kombuchas. First, a survey was made in the hypermarkets of the city, and later in the stores of natural products. These samples were transported in ice coolers to the laboratory and stored in the refrigerator $\left( \pm 7^{\circ} \mathrm{C}\right)$ for possible analysis.

\section{Physicochemical analyses}

The physicochemical analyses were performed according to the methodologies of the Adolfo Lutz Institute [15] for pH, moisture, ash, glucose reducing glycides and non-reducing sucrose. 
Humidity

The Kombuchas samples were weighed in an analytical crucible, and soon after, they were transported inside the desiccator, with silica gel to the greenhouse (Nova Ética, model 404 - 3D) where they stayed for a period of 24 hours in direct drying at $105^{\circ} \mathrm{C}$ until the constant weight was obtained [15].

\section{Ashes}

The incineration method was used in Muffle at $700^{\circ} \mathrm{C}$ for one hour, when the residue was obtained from the determination of moisture [15]. After the samples had been in the greenhouse for 24 hours, they were transported inside the desiccator with gel silica to the Muffle (Digimec, Model SHM), where they stayed for a period of 1 hour, at a temperature of $700^{\circ} \mathrm{C}$. After this period, they were kept in the desiccator with gel silica until they were at room temperature. They were weighed on analytical scale scans to determine the ash value.

\section{PH determination}

The $\mathrm{pH}$ values were measured using a digital pHmeter (KASVI, model K39-0014PA). Being, to perform the evaluation, the equipment was calibrated with known $\mathrm{pH}$ solutions, according to the manufacturer's instructions. Between the exchange of one sample to another, the probe was cleaned with distilled water so that there was no change in the $\mathrm{pH}$ value [15].

Reducing glycidia in glucose and non-reducing glycides in sucrose

The methods of glucose and non-reducing glycides in sucrose were used to determine the sugars, according to fehlling methodology, and the result was expressed in grams of glucose and sucrose per $100 \mathrm{~g}$ of the sample [15]. The samples were weighed in a beaker and subsequently supplemented with distilled water up to the $100 \mathrm{ml}$ mark. The ones in need were filtered and then transferred to a burette. In another beaker, a solution containing Fehlling A and Fehlling B was made, and $40 \mathrm{ml}$ of distilled water was supplemented. Soon after, they were taken to the heating plate to boil and titration. The faster the titration, the higher the content of sugars present, and the longer it takes, the lower the sugar content.

\section{Antioxidant compounds}

\section{Ascorbic acid}

Ascorbic acid was identified by weighing a quantity of the sample in a beaker and adding sodium bicarbonate and ferrous sulfa- te. This reaction made the sample go from a rosy color, which is characteristic of the analyzed strawberry flavor, to a dark brown color [15]. The solution that had the presence of the antioxidant presented a transparent coloration after the addition of sulfuric acid at $10 \%$.

\section{Galatos}

The gallates were identified from the extraction of these with $72 \%$ alcohol in a separation funnel, and later a reaction with ammonium hydroxide was made. The solution that had the presence of gallates, should present a rosy coloration [15].

\section{Data analysis}

With the aid of software R [16], the data were tabulated to variance analysis (ANOVA) for repeated measurements, and thus verify the homogeneity of the means. The means that were homogeneous ( $p>0.05$ ) were submitted to duncan's test. The $p$ values were considered significant when less than 0.05. Four treatments were formulated, one for each kombucha sample (A, B, C and D). The analyses were performed in triplicates.

\section{Results}

The analysis of variance shows that all analyses showed significant differences between kombuchas samples (Table 1).

\begin{tabular}{|c|c|c|c|c|c|c|}
\hline $\begin{array}{c}\text { Sources } \\
\text { of varia- } \\
\text { tion }\end{array}$ & GL & \multicolumn{5}{|c|}{ Middle Square } \\
\cline { 2 - 7 } & $\mathbf{p H}$ & $\begin{array}{c}\text { Humi- } \\
\text { dity } \\
\text { (\%) }\end{array}$ & $\begin{array}{c}\text { Ashes } \\
\mathbf{( \% )}\end{array}$ & $\begin{array}{c}\text { Reducing } \\
\text { sugars (\% } \\
\text { glucose) }\end{array}$ & $\begin{array}{c}\text { Sugars not } \\
\text { reducers } \\
\text { (\% sucrose) }\end{array}$ \\
\hline $\begin{array}{c}\text { Treat- } \\
\text { ment }\end{array}$ & 3 & $0,22^{*}$ & $49,36^{*}$ & $46,11^{*}$ & $\begin{array}{c}24,99^{*} \\
274,68^{*}\end{array}$ & \\
\hline Residue & 8 & 0,005 & 0,13 & 0,07 & 0,16 & 1,93 \\
\hline CV (\%) & & 2,26 & 0,38 & 4,39 & 10,90 & 11,54 \\
\hline
\end{tabular}

Table 1: Summary of variance analysis, by mean square, referring to $\mathrm{pH}$, moisture, ash, glycides in glucose and sucrose of different kombucha brands.

Source: Search data.

$\mathrm{CV}=$ Coefficient of Variation; GL= Degree of Freedom; ns= Not Significant, ${ }^{*}=$ Significant at $\mathrm{p}<0.0001$.

As shown in figure 1, the samples showed significant differences for moisture and ash, differing from each other. Sample B (99.39\%) presented a higher humidity value than the other patients. Sample C (89.82\%) presented lower moisture value compared to other samples. Regarding the ashes, the C sample (10.16\%) presented higher values and the B sample (0.90\%) lower values. 

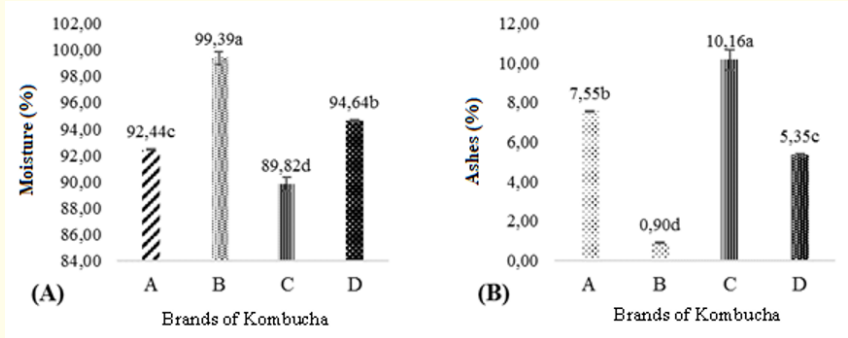

Figure 1: Average values $( \pm \mathrm{EP})$ values of moisture $(\mathrm{A})$ and ash $(\mathrm{B})$ of different kombucha brands.

Source: Search data.

a,b,c Averages followed by different lowercase letters differ according to the Duncan test $(\mathrm{P}<0.05)$.

Figure 2 shows the mean $\mathrm{pH}$ values of the samples. Samples B and $\mathrm{C}$ presented similar $\mathrm{pH}$ values, and higher than samples $\mathrm{A}$ and D.

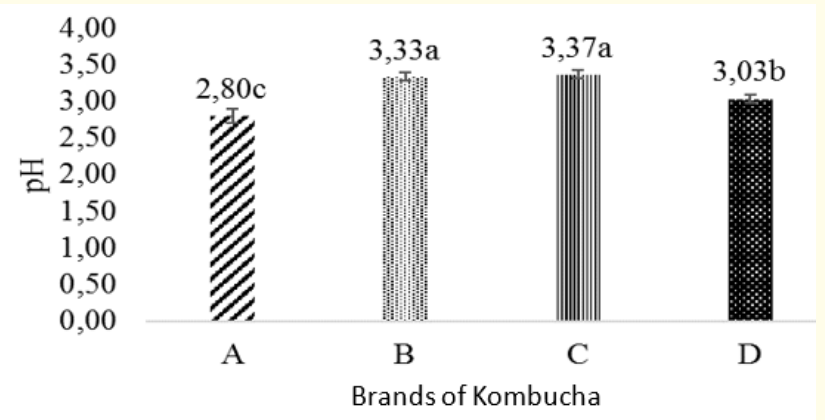

Figure 2: Mean $\mathrm{pH}( \pm \mathrm{EP})$ values of different Kombucha brands.

Source: Search data.

${ }^{\text {a,bc }}$ Averages followed by different lowercase letters differ according to the Duncan test $(\mathrm{P}<0.05)$.

The analysis of variance presented in Table 1 shows that there was a significant difference between the samples for the analysis of glucose reducing sugars and non-reducing sugars in sucrose (Figure 3). All samples differed significantly from each other in terms of reducing sugar content, with sample $C(7.77 \%)$ presenting higher values, while sample A $1.23 \%)$ lower values. For non-reducing sugars, there wasalso a significant difference between allsamples, with sample C (23.78\%) presenting higher sucrose values and sample B (1.05\%) lower values.

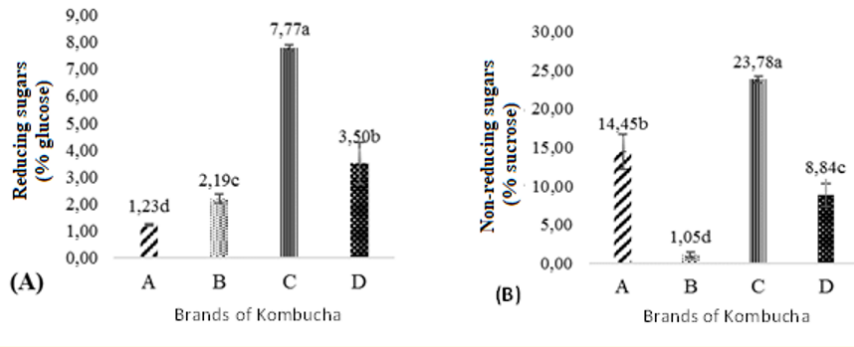

Figure 3: Mean values $( \pm \mathrm{EP})$ of glycides $(\mathrm{A})$ and sucrose $(\mathrm{B})$ of different brands of Kombuchas.

Source: Search data.

a,b,c Averages followed by different lowercase letters differ according to the Duncan test $(\mathrm{P}<0.05)$.

Table 2 presents the results for the antioxidant analyses of the four Kombuchas samples. It can be observed that none of the samples presentor the antioxidant gallates in their composition. However, all samples showed the antioxidant ascorbic acid.

\begin{tabular}{|c|c|c|}
\hline Antioxidant & March & Result \\
\hline Ascorbic acid & $\mathrm{A}$ & Present \\
\cline { 2 - 3 } & $\mathrm{B}$ & Present \\
\cline { 2 - 3 } & $\mathrm{C}$ & Present \\
\cline { 2 - 3 } & $\mathrm{D}$ & Present \\
\hline \multirow{4}{*}{ Galatos } & $\mathrm{A}$ & Absent \\
\cline { 2 - 3 } & $\mathrm{B}$ & Absent \\
\cline { 2 - 3 } & $\mathrm{C}$ & Absent \\
\cline { 2 - 3 } & $\mathrm{D}$ & Absent \\
\hline
\end{tabular}

Table 2: Presence of Antioxidants in Kombuchas samples. Source: Search data.

\section{Discussion}

Humidity

Figure 2 (A) shows that all the analyzed brands showed significant differences in relation to the respective humidity values. Brand A (92.44\%) presented a value closer to the D mark (94.64\%) and the B mark (99.39\%) presented the highest humidity values.

According to Resolution 12 CNNPA 12 of 1978, the minimum humidity for green tea-based beverages is $28 \%$. Therefore, the 
humidity values of the Kombuchas analyzed were within the standards required by the current legislation [17].

Ashes

Ash refers to the content of inorganic residues in food or fixed mineral residue (sodium, potassium, magnesium, calcium, iron, phosphorus, copper, chloride, aluminum, zinc, manganese and other mineral compounds) remaining from the burning of organic matter in muffle at high temperatures [18].

No indications were found in the legislation regarding the ash content for fermented beverages, but the results indicate that the B mark $(0.90 \%)$ contains the lowest ash content and the c mark $(10.16 \%)$ obtained the highest ash value. One of the reasons for the high ash content in the $\mathrm{C}$ mark is the fact that the fresh fruit was used, as shown in the ingredients on the drink label and the other brands used the fruit juice, thus presenting less residues.

The ash content in the beverage is caused by the presence of tea and the addition of the fruit in order to flavor and improve the palatability of the product. According to the data from the table of chemical composition of the food, the ash content found in the strawberry is $0.4 \mathrm{~g}$ per $100 \mathrm{~g}[19,20]$.

Another possibility would be due to a possible contamination of the products by impurities of inorganic origin, which may result from the production process or even contamination stemming from the fact that the strawberry is grown outdoors, being exposed to dust particles, leaves and insects [21].

pH

$\mathrm{pH}$ is one of the most important parameters affecting kombucha's fermentative microenvironment. Some acids formed during the process, such as acetic acid and gliconic acid are responsible for some of the biological properties and antimicrobial pharmacological activities against Staphylococcus aureus, Salmonella sp, E. coli, Streptococcus sp, in addition to inhibiting the growth of molds and yeasts [22].

According to authors [22], the pH should not be below 3.0 so that the drink can be ingested without causing damage to the gastrointestinal tract. The ideal $\mathrm{pH}$ for the beverage to have good palatability and biological properties is between 4.0 and 5.0. The period for obtaining this $\mathrm{pH}$ is mainly dependent on the ambient temperature and the fermentation conditions of the culture medium [22].

According to legislation [23], the ideal pH for Kombuchas is at least 2.5 and maximum 4.2. Thus, as shown in the results, the four brands (A, B, C and D) obtained $\mathrm{pH}$ values considered ideal for fermented beverages such as Kombucha, by legislation. Thus, the results showed that the $\mathrm{pH}$ of brand A presented a value of 2.80, being the only brand to obtain a value lower than the ideal $\mathrm{pH}$ so that the beverage is ingested without causing damage to the gastrointestinal tract. Samples B, C and D obtained a $\mathrm{pH}$ value above 3.0, thus being considered the ideal drink for consumption [21]. The $\mathrm{C}$ brand (3.37\%) was kombucha that presented the highest $\mathrm{pH}$ value becoming close to ideal [21]. Kombuchas presented low pH values due to the fermentation process, temperature, preparation time [7].

\section{Glucose reducing glycides}

It can be observed that sample $C$ presented higher content of glycides $(7.77 \%)$ glucose reducers when compared to the other samples. This may be due to a greater addition of the sugar used for its production. There is not yet a following parameter of reducing sugars for Kombucha, therefore the present work obtained the result between $1.23 \mathrm{~g} / 100 \mathrm{~mL}$ and $7.77 \mathrm{~g} / 100 \mathrm{~mL}$.

According to the research carried in 2018 [24], the values of reducing sugars in Kombuchas ranged from $0.28 \mathrm{~g} / 100 \mathrm{~mL}$ to $3.17 \mathrm{~g} / 100 \mathrm{~mL}$. A difference was identified in the values obtained, compared to the value of reducing sugars in Kombucha C (7.77\%), which presented a higher amount of these sugars. The lack of legislation indicating minimum or maximum values allowed makes it difficult to compare.

\section{Non-reducing glycidia in sucrose}

It was observed that the samples showed a significant difference regarding non-reducing sugars. Kombucha C (23.78\%) has a higher content of non-reducing glycides in sucrose compared to other samples. The kombuchas labeling did not inform the quantity of nutrients present in three samples (A, C and D), i.e. only cited the ingredients used in their preparation, not presenting nutritional information. According to research of Richter and Lannes [25] due to sucrose being an ingredient that makes the products tastier, it is incorporated in larger quantities in food, to make them more 
attractive. As Kombuchas have more acidic flavors, the incorporation of sucrose causes this flavor to be masked.

Sample B, in turn, presented the lowest level of sucrose, showing that it was less used in the preparation of Kombucha, being a healthier option.

\section{Antioxidants}

Ascorbic acid (vitamin C) is a water-soluble vitamin, of great importance for collagen synthesis and tissue repair. It also plays a significant role in the metabolism of tyrosine, carbohydrates, iron, in the conversion of folic acid into folinic acid, in the synthesis of lipids and proteins, resistance to infections and in cell respiration. In addition to supporting the immune system, contributing to antioxidant properties, which helps neutralize free radicals in cells [26]. The recommended dose of ascorbic acid is given by DRI (Dietary Reference Intakes), which recommends the recommendation of 90 $\mathrm{mg}$ for men and $75 \mathrm{mg}$ for adult women [27].

Samples A, B, C and D present the presence of ascorbic acid due to the use of strawberry, a fruit that is rich in vitamins $C, A, E, B 5$, B6, and minerals such as calcium, potassium, iron, selenium and magnesium [28].

For gallates, the absence of this antioxidant was found in all samples. According to some authors [29,30], one of the explanations for this absence is the preparation mode, the fermentation period and the low concentration of strawberry, a raw material used in order to aid in fermentation and provide flavor to the drink.

Another possible explanation of gives by the non-use of the fruit but, industrialized strawberry juice, which can also explain the light red presented in the drinks. In the strawberry is anthocyanins, composed of great concentration and responsible for characterizing the red color. This compound is highly sensitive and can be affected by the processing and fermentation method, which can alter the chemical and sensory physical characteristics [29-31].

\section{Conclusion and Final Considerations}

Kombucha is gaining more and more space in the Brazilian market for adapting to the interests related to the healthiness that are on the rise. All Kombuchas analyzed in the study presented the presence of the antioxidant ascorbic acid, a small amount of reducing and non-reducing sugars, besides the $\mathrm{pH}$ being in accordance with the legislation, the Kombuchas presented satisfactory results for consumption.

According to the results obtained, sample B obtained better results, with a lower percentage of sugar compared to the other samples, thus being a healthier option for consumption. Only one brand presented nutritional information on the label, so it is important to highlight the need to add nutritional information to food labels, since they inform all nutrients and their quantities, which helps in the act of consumer choice to a given food.

Another important factor is the need to add more information in current legislation, such as the physical-chemical and sensory characteristics of the product.

\section{Bibliography}

1. Rodrigues RS., et al. "Physical and chemical characteristics of Kombucha based on hibiscus tea (Hibiscus sabdariffa, L.)". In: Food Safety Symposium 6 (2018): Gramado. The anais Gramado: SBCTA Regional, RS (2018): 72-78.

2. Moura A. "Monitoring kombucha's fermentation process of mate tea. Completion of course work (Graduation in Nutrition) - Federal University of Pernambuco". Vitória de Santo Antão (2019).

3. Brazil. Ministry of Health. National Health Surveillance Agency. Resolution RDC No. 18 of April 30. Technical Regulation that establishes the basic guidelines for analysis and proof of functional and or health properties alleged in food labeling, contained in the annex of this ordinance. Official Gazette, Executive Branch (1999).

4. Cardoso., et al. "Physicochemical and antimicrobial evaluation of Kombucha Probiotic (Medusomyces gisevii lindau) and comparative analysis with other probiotics marketed in Brazil". Nutrition Brazil 2 (2018).

5. Maia YLM., et al. "Kombucha: Features and bilogical aspects". RRS-FESGO 3.1 (2020): 114-123.

6. Schroeder J. "Kombucha fermented from acerola residue". $47 \mathrm{f}$. Completion of course work (Graduation in Food Engineering) - Federal University of Santa Catarina. Florianópolis (2019).

7. Greenwalt CJ., et al. "Kombucha, the fermented tea: Microbiology, composition, and claimed health effects". Journal of Food Protection 63.7 (2000): 976-981. 
8. Paludo. "Development and characterization of kombucha obtained from green tea and yerba mate extract: artisanal process and laboratory scale". $47 \mathrm{f}$. Completion of course work (Graduation in Food Engineering) - Federal University of Rio Grande do Sul. Porto Alegre (2017).

9. Jayabalan R., et al. "Biochemical characteristics of tea fungus produced during Kombucha fermentation". Food Science and Biotechnology, Seoul 19.3 (2010): 843-847.

10. Rubert A., et al. "Vitamins: a brief review". Young Researchers Journal 7.1 (2017): 30-45.

11. Cavalari TG and Sanches R. "The effects of vitamin c". Revista saúde em foco (2018): 749-765.

12. Watawana MI., et al. "Health, Wellness, and Safety Aspects of the Consumption of Kombucha". Journal of Chemistry 2015.1 (2015): 1-11.

13. Bruschi JS., et al. "The resurgence of kombucha tea”. Journal of Scientific Initiation and Extension - REIcEn 1 (2018): 162-168.

14. Medeiros SCG., et al. "Effects in Vitro And in Vivo". Infarma Pharmaceutical Sciences 31.2 (2019): 73-79.

15. Adolfo Lutz Institute. "Physical-chemical methods for food analysis". 1 ed. digital. São Paulo, (2010).

16. R Core Team (2016). "R: A language and environment for statistical computing”. R Foundation for Statistical Computing, Vienna (2016).

17. Brazil. "Ministry of Health. National Health Surveillance Agency. Resolution CNNPA No. 12. Identity and quality standards for food and beverages". Official Gazette, Brasilia (1978).

18. Zambiazi RC. "Análise Físico Química de Alimentos". Pelotas: Editora Universitária/UFPEL. SAS Institute. System for Information, versão (2010): 202.

19. USDA - United States Department of Agriculture. "Table of chemical composition of food" (2020).

20. UNICAMP - State University of Campinas. "Brazilian table of food composition" (2020).

21. Cecato AP., et al. "Sistemas de cultivo na produção e qualidade de cultivares de morango. Faculdade de Agronomia e Medicina Veterinária da Universidade". Rio Grande do Sul 35.4 (2013).
22. Villarreal-Soto SA., et al. "Impact of fermentation conditions on the production of bioactive compounds with anticancer, anti-inflammatory and antioxidant properties in kombucha tea extracts". Journal of Process Biochemistry. Toulouse, France (2019): 44-54.

23. Brazil. Normative Instruction No. 41, September 17, 2019. "It establishes the standard of identity and quality of kombucha throughout the national territory". Official Gazette 181 (2019): 13.

24. Santos YM., et al. "Chemical characterization of Kombucha based on hibiscus and black teas". Brazilian Journal of Agrotechnology. Ipameri 8.3 (2018): 32-37.

25. Richter M and Lannes SCS. "Ingredientes usados na indústria de chocolates". Revista Brasileira de Ciências Farmacêuticas 43.3 (2007): 357-369.

26. Santana AA. "Effects of in Management of a decaffeinated green cha extract rich in epigallocatechin-3-gallate on lipid metabolism of mice fed a hyperlipidic diet". Federal University of São Paulo (UNIFESP) 75 (2014).

27. Institute of Medicine (US) Panel on Dietary Antioxidants and Related Compounds. Dietary Reference Intakes for Vitamin C, Vitamin E, Selenium, and Carotenoids. Washington (DC): National Academies Press (US); (2000): 5.

28. Simionato LM., et al. "Compositional determination of kombuchas samples plus fruit savers". FAG Journal of Health 2.2 (2020): 252.

29. Matsubara S and Rodriguez-Amaya DB. "Catechin and teaflavine contents in teas sold in Brazil". Food Technology Science, Campinas 26.2 (2006): 401-407.

30. Hornedo-Ortega R., et al. "Influence of fermentation process on the anthocyanin composition of wine and vinegar elaborated from strawberry". Journal of Food Science 82 (2017): 364-372.

31. Simioni LY. "Development of smoothie fermented by kombucha microorganisms based on consumption profile, chemical composition, bioactive compounds and sensory description". Ponta Grossa (2019). 


\section{Assets from publication with us}

- Prompt Acknowledgement after receiving the article

- Thorough Double blinded peer review

- Rapid Publication

- Issue of Publication Certificate

- High visibility of your Published work

Website: www.actascientific.com/

Submit Article: www.actascientific.com/submission.php

Email us: editor@actascientific.com

Contact us: +919182824667 